Article

\title{
Facile Synthesis of P25@Pd Core-Shell Catalyst with Ultrathin Pd Shell and Improved Catalytic Performance in Heterogeneous Enantioselective Hydrogenation of Acetophenone
}

\author{
Xiuyun Gao, Lulu He, Juntong Xu, Xueying Chen * (1) and Heyong He \\ Department of Chemistry and Shanghai Key Laboratory of Molecular Catalysis and Innovative Materials, \\ Fudan University, Shanghai 200433, China; 16210220034@fudan.edu.cn (X.G.); 14110220027@fudan.edu.cn (L.H.); \\ 15307110311@fudan.edu.cn (J.X.); heyonghe@fudan.edu.cn (H.H.) \\ * Correspondence: xueyingchen@fudan.edu.cn; Tel.: +86-21-3124-2978
}

Received: 16 May 2019; Accepted: 5 June 2019; Published: 9 June 2019

check for updates

\begin{abstract}
Heterogeneous enantioselective hydrogenation is an ideal method for synthesizing important chiral compounds in pesticides and pharmaceuticals. Up to the present, supported noble-metal catalysts are most widely studied in heterogeneous enantioselective hydrogenations. However, it is found that the weak interactions existing on the surface of support may have negative effects on the enantioselectivity. Herein, a new category of $\mathrm{TiO}_{2}$ (Aeroxide ${ }^{\circledR}$ P25) supported Pd catalyst with ultrathin Pd shell was successfully prepared via a simple strategy based on the reduction of $\mathrm{Pd}^{\mathrm{I}}$ carbonyl complex. Characterization results show that a well-dispersed ultrathin Pd shell with an average thickness of $\sim 1.0 \mathrm{~nm}$ and a Pd loading of $36 \mathrm{wt} . \%$ was formed over the surface of P25 support. By excluding the negative weak interactions from the support, the P25@Pd core-shell catalyst with unique electronic properties of Pd exhibits higher activity and enantioselectivity than that of Pd/P25 catalyst prepared by the impregnation method and unsupported Pd black catalyst in the enantioselective hydrogenation of acetophenone.
\end{abstract}

Keywords: P25@Pd; core-shell; heterogeneous enantioselective hydrogenation; acetophenone

\section{Introduction}

With the wide application of optically pure chiral compounds in pesticides, pharmaceuticals and fragrances, it is particularly important to develop effective preparation methods for synthesizing single-enantiomer compounds [1-3]. Among the many established methods, enantioselective hydrogenation over heterogeneous catalysts is one of the most ideal strategies owing to its inherent operational and economic advantages, e.g., atom economy, easy separation and recovery of catalysts. Therefore, it has shown great potential in industrial research and caused extensive concern in academic circles [1-4].

The enantioselective hydrogenation of acetophenone is a probe reaction widely chosen for heterogeneous asymmetric hydrogenation studies, since it is a good example of competitive reaction and its target product (chiral 1-phenylethanol) is related to the production of pharmaceutical intermediates [5-9]. However, the enantioselectivity reported so far over traditional supported noble-metal (e.g., Pd, Pt) catalysts is generally low and further improvements are still needed.

Nowadays, chirally modified supported noble-metal catalysts have been most widely used in heterogeneous enantioselective hydrogenations [2-7,9-14]. It is well known that the catalytic performance of the supported metal catalysts strongly depends on the metal particle size. Thus, to make the metal nanoparticles disperse well for achieving high activity, the metal loading of the 
catalysts studied in the literature is generally less than $5 \mathrm{wt} . \%$. However, it is found that the various weak interactions (such as hydrogen bond, physical adsorption and van der Waals force) existing on the surface of the support are in the same energy range with the energy difference between the two transition states of R- and S-products in chiral reactions $(<15 \mathrm{~kJ} / \mathrm{mol})$, which may affect the chiral recognition process and thus have a negative effect on the enantioselectivity [15]. Baiker et al. found that the acidity and basicity of the support could significantly affect both the chemoselectivity and the enantioselectivity in the enantioselective hydrogenation of activated ketones [16]. Therefore, the exposure of support surface adds the complexity in elucidating the nature of the chiral recognition on metal catalysts in heterogeneous enantioselective hydrogenation reactions. Thus, to reduce the difficulty in heterogeneous asymmetric hydrogenation studies and achieve higher enantioselectivity, it is highly desirable to exclude the negative weak interactions existing on the surface of the support.

It is well known that supported metal catalysts with core-shell structure have attracted much attention because of their unique structure and better performance in some catalytic reactions $[17,18]$. Therefore, if we could form an ultrathin metal layer on the surface of the support, it may not only eliminate the adverse effect of weak interactions from the support on heterogeneous asymmetric hydrogenations, but also affect the electronic properties of noble-metal catalysts, which is of great significance in both fundamental and practical aspects.

In this work, a new category of $\mathrm{TiO}_{2}$ (Aeroxide ${ }^{\circledR}$ P25) supported Pd catalyst with unique core-shell structure (P25 core and Pd ultrathin shell, denoted as P25@Pd) was tactically prepared by a facile strategy under mild conditions based on the reduction of $\mathrm{Pd}^{\mathrm{I}}$ carbonyl complex [19] over the surface of the P25 support. The as-prepared P25@Pd catalyst exhibits a well-dispersed ultrathin Pd shell with an average thickness of $\sim 1.0 \mathrm{~nm}$ and a Pd loading of $36 \mathrm{wt} . \%$. The formation of the ultrathin Pd shell over the surface of the P25 support excludes the negative weak interactions from support and the resulting P25@Pd core-shell catalyst exhibits improved activity and enantioselectivity in the enantioselective hydrogenation of acetophenone. The unique electronic properties of $\mathrm{Pd}$ influenced by the interaction between the ultrathin Pd shell and the P25 support also probably have a positive effect on the enantioselectivity. The new category of supported noble-metal catalyst with ultrathin metal shell could be promising for heterogeneous asymmetric catalytic studies.

\section{Results and Discussion}

\subsection{Morphology of the P25@Pd Catalyst}

Figure 1 shows the representative transmission electron microscopy (TEM) images of the P25 support and the as-prepared P25@Pd core-shell catalyst. The P25 support displays a nanoparticle morphology with an average particle size of ca. $21 \mathrm{~nm}$ (Figure 1a). As compared to the P25 support, the much darker outlines of the nanoparticles in P25@Pd catalyst (Figure 1b) indicate that Pd metal is deposited over the surface of the P25 support. To further visualize the core-shell structure of the P25@Pd catalyst, a high angle annular dark field scanning TEM (HAADF-STEM) image is presented in Figure 1c, which clearly exhibits the coverage of the Pd shells (brighter areas in contrast). The average thickness of the Pd shell calculated based on the statistic calculation (Figure 1d) is ca. $1.0 \mathrm{~nm}$. Figure 1e provides a typical high resolution TEM (HRTEM) image of a P25@Pd nanoparticle. The interplanar spacing of $0.23 \mathrm{~nm}$ can be observed in the Pd shell on the P25@Pd nanoparticle, ascribable to (111) lattice spacing of face-centered cubic (fcc) Pd [20]. A d-spacing of $0.35 \mathrm{~nm}$ observed in the P25 core corresponds to the (101) planes of anatase $\mathrm{TiO}_{2}$ [21]. Figure $1 \mathrm{f}$ presents the typical elemental mapping images of the P25@Pd catalyst. The results clearly demonstrate the successful coverage of Pd shell over the surface of the P25 support, unambiguously confirming the P25 core/Pd shell structure. As detected by inductively coupled plasma atomic emission spectroscopy (ICP-AES), the weight percentage of Pd in the P25@Pd catalyst is 36\%, which is in good accordance with the energy dispersive X-ray emission (EDX) analysis ( $\mathrm{Pd} /$ Ti molar ratio of 0.43$)$. 

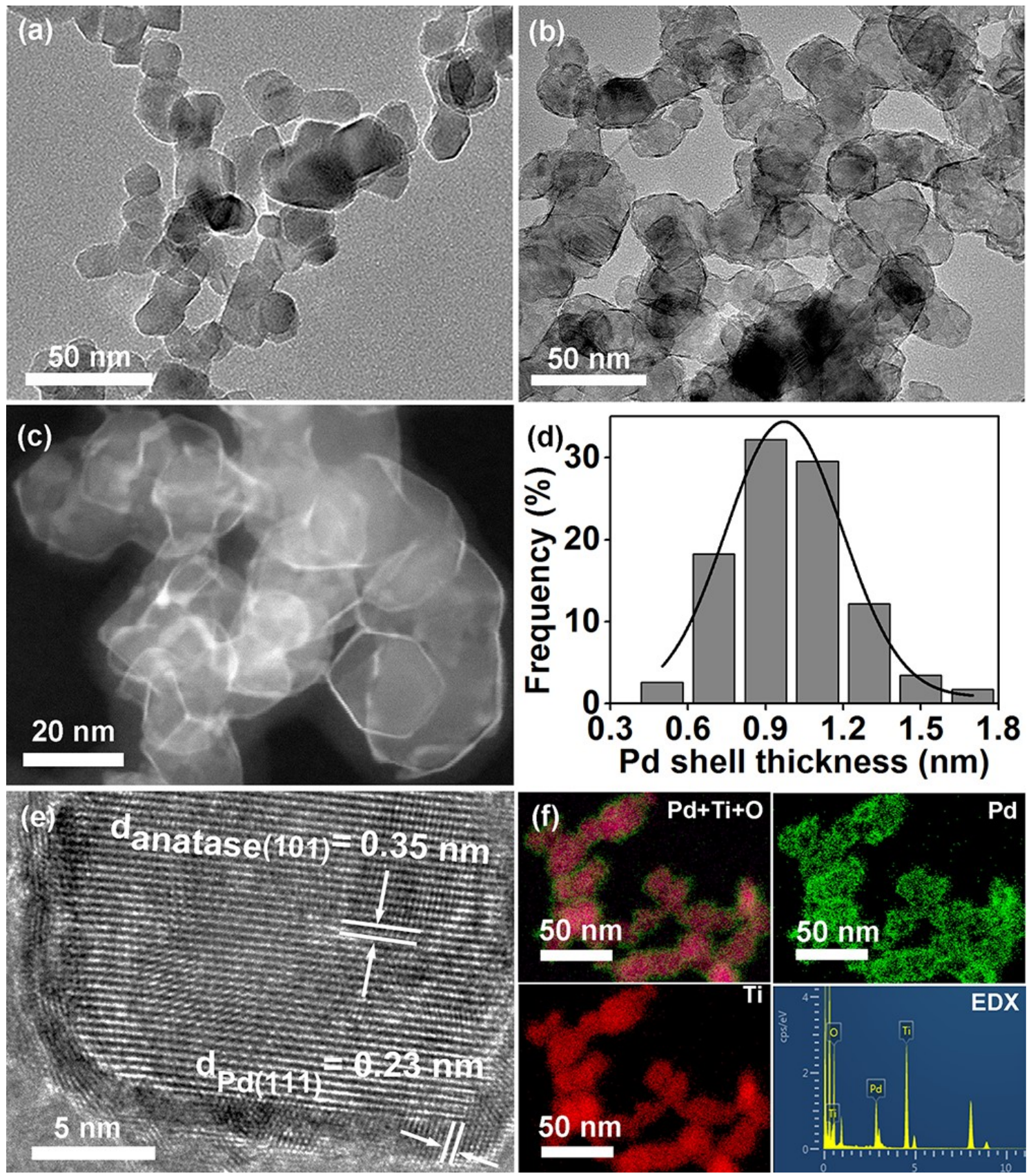

Figure 1. Transmission electron microscopy (TEM) images of (a) P25 support and (b) P25@Pd core-shell catalyst; (c) high angle annular dark field scanning (HAADF-STEM) image, (d) Pd shell thickness distribution, (e) high resolution TEM (HRTEM) image, and (f) elemental mapping results of P25@Pd core-shell catalyst.

\subsection{Structural Properties of the P25@Pd Catalyst}

The Brunauer-Emmett-Teller (BET) specific surface area of the P25@Pd catalyst is $53.4 \mathrm{~m}^{2} \mathrm{~g}^{-1}$, which is slightly larger than that of the parent P25 support $\left(49.7 \mathrm{~m}^{2} \mathrm{~g}^{-1}\right)$. The X-ray diffraction (XRD) measurements were carried out to identify the phase and lattice structures of the parent P25 support and P25@Pd core-shell catalyst. As shown in Figure 2a, there are several diffraction peaks in the parent P25 support, which can be fully indexed to anatase and rutile $\mathrm{TiO}_{2}$ (JCPDS card no. 89-4921, 89-4920) [21]. In addition to the diffraction peaks of the parent P25 support [21], two additional broad diffraction peaks at $2 \theta$ of 40.0 , and $46.5^{\circ}$ can be clearly observed, corresponding to (111) and (200) 
reflections of fcc Pd (JCPDS card no. 89-4897). The lattice constant of Pd in P25@Pd core-shell catalyst calculated by peak fitting (Figure $2 \mathrm{~b}$ ) is ca. $0.389 \mathrm{~nm}$, which is similar to that of the Pd black sample. According to the fitting results, the intensity ratio of the $\operatorname{Pd}(111)$ and $\operatorname{Pd}(200)$ peaks is 4.14, which is 1.8 times that of the Pd black sample (2.27), indicating that the ultrathin Pd shell in the P25@Pd catalyst has (111) preferred orientation.
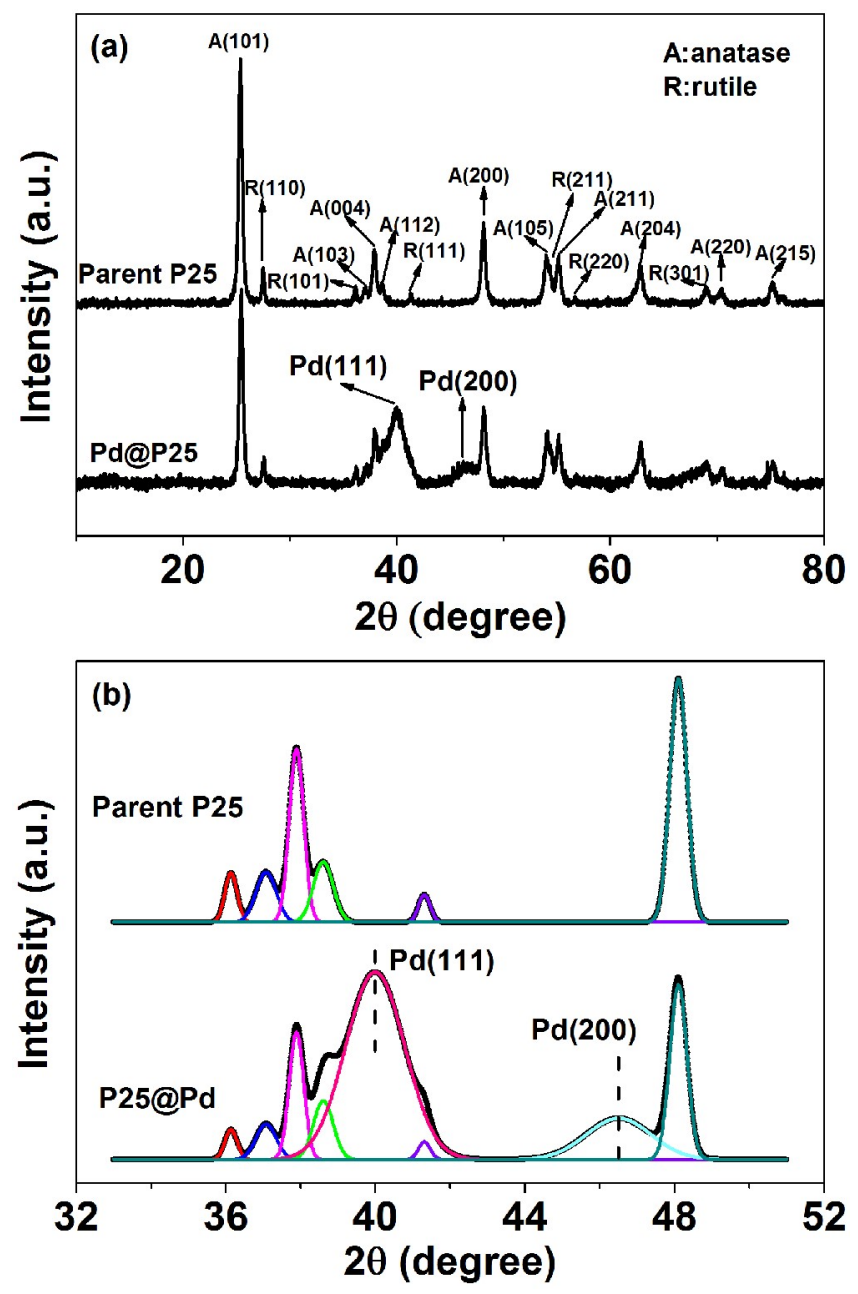

Figure 2. X-ray diffraction (XRD) patterns of parent P25 support and P25@Pd core-shell catalyst: (a) Experimental data, (b) peak fitting results.

\subsection{Study on the Formation of P25@Pd Core-Shell Structure}

In order to investigate the formation of P25@Pd core-shell structure, a set of comparative experiments were carefully carried out. Without the addition of P25 support, only ultrathin Pd nanosheets are formed by the reduction of $\mathrm{Pd}^{\mathrm{I}}$ carbonyl complex [19] (Figure 3a). In the presence of P25 support, the reduction of $\mathrm{Pd}^{\mathrm{I}}$ carbonyl complex [19] completely occurs on the surface of $\mathrm{P} 25$ support to form the P25@Pd core-shell catalyst and no isolated Pd nanosheets could be observed. However, when we replace the $\mathrm{P} 25$ support with mesoporous carbon, $\gamma-\mathrm{Al}_{2} \mathrm{O}_{3}$ or $\mathrm{SiO}_{2}$ support, instead of forming core-shell structure, isolated ultrathin Pd nanosheets aggregated together or small Pd nanoparticles located on the surface of the support are observed (Figure $3 \mathrm{~b}-\mathrm{d}$ ). Thus, the preferred deposition of Pd over the P25 support to form the core-shell structure could be possibly attributed to the unique interaction between Pd and the P25 support [22-24]. Due to the interaction between Pd and the P25 support, the $\mathrm{Pd}^{\mathrm{I}}$ carbonyl complex [19] is prone to be reduced over the surface of each P25 nanoparticle, facilitating the uniform coating of Pd ultrathin shell over the P25 nanoparticle surface to form the core-shell structure. The detailed formation mechanism of the core-shell structure still requires further 
study. For comparison, we also synthesized Pd/P25 catalyst with the same Pd loading by impregnation method with $\mathrm{N}_{2} \mathrm{H}_{4} \cdot \mathrm{H}_{2} \mathrm{O}$ as the reductant. As shown in Figure 3e, Pd nanoparticles on P25 support are varied in size and tend to aggregate together in the $\mathrm{Pd} / \mathrm{P} 25$ catalyst, which is totally different from that of the P25@Pd core-shell catalyst. The molar ratio of Pd/Ti is similar to that of the P25@Pd catalyst as verified by EDX analysis (Figure 3f).

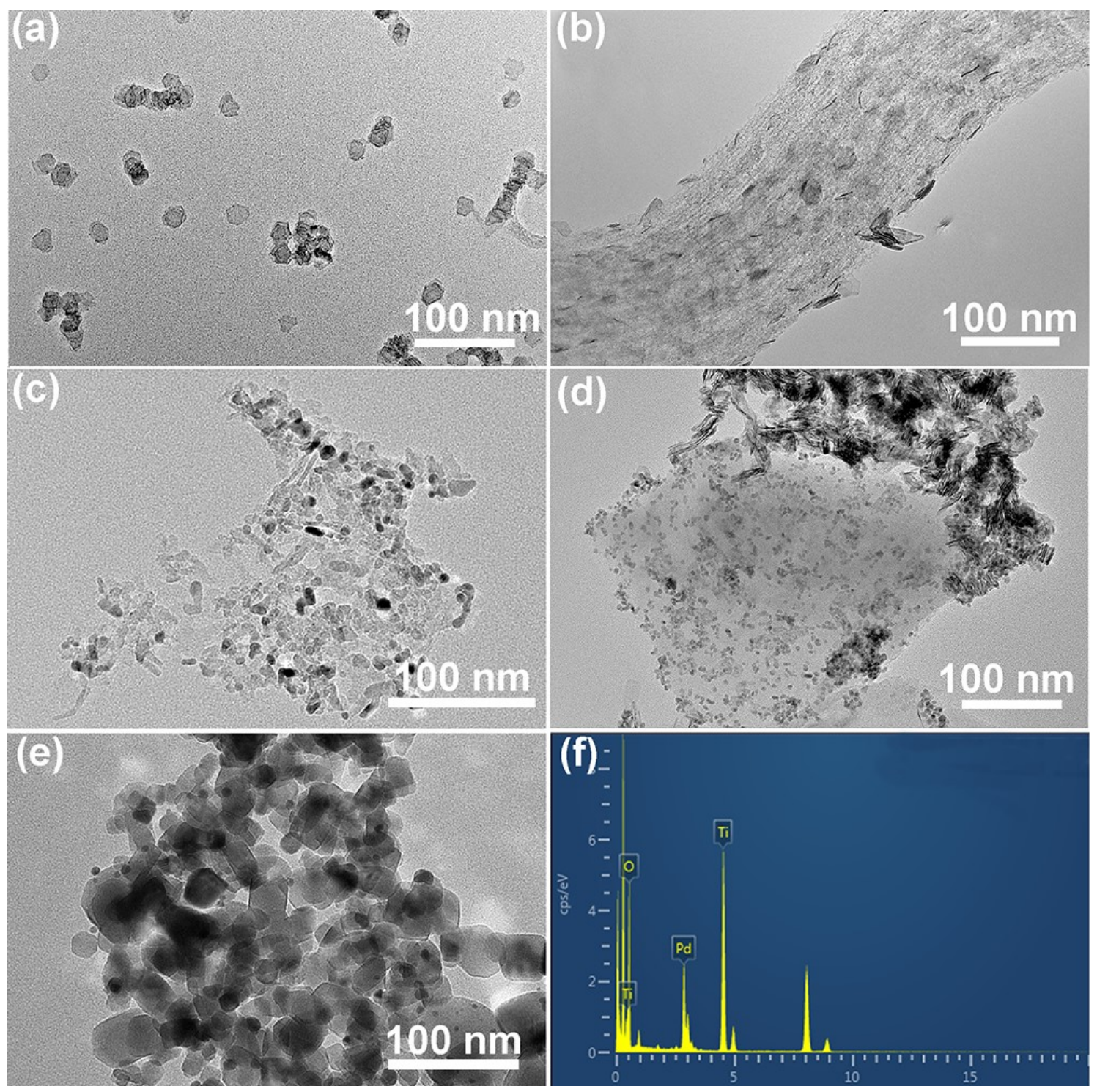

Figure 3. TEM images of (a) Pd nanosheets obtained in the absence of P25 support, (b, c, d) Pd catalyst prepared by the same reduction procedure except using mesoporous carbon, commercial $\gamma-\mathrm{Al}_{2} \mathrm{O}_{3}$, and $\mathrm{SiO}_{2}$ as support, respectively; (e) TEM image and (f) energy dispersive X-ray emission (EDX) results of $\mathrm{Pd} / \mathrm{P} 25$ catalyst prepared by traditional impregnation method.

\subsection{Electronic Properties of the P25@Pd Catalyst}

X-ray photoelectron spectroscopy (XPS) was utilized to detect the electronic state of elements in P25@Pd catalyst. Figure 4a presents the Pd 3d core level spectrum of the P25@Pd core-shell catalyst. The Pd $3 d$ core-level line could be fitted with two main doublets with the binding energy (BE) of the $P d 3 d_{5 / 2}$ peaks at 334.9 and $336.1 \mathrm{eV}$, corresponding to metallic $\mathrm{Pd}$ and $\mathrm{Pd}^{\delta+}$ species, respectively $[23,25,26]$. The Ti 2p spectrum of P25@Pd core-shell catalyst (Figure $4 \mathrm{~b}$ ) is dominated by species in the $\mathrm{Ti}^{4+}$ oxidation state at the BE of 458.8 and $464.5 \mathrm{eV}$, which is consistent with the typical Ti $2 \mathrm{p}_{3 / 2}$ and Ti $2 \mathrm{p}_{1 / 2}$ values for 
P25 support [27-29]. The surface Pd/Ti atomic ratio of the P25@Pd catalyst derived from XPS data is evaluated to be 0.99 , which is more than twice that of the bulk composition measured by ICP and EDX, reflecting the surface enrichment of the Pd shell.

To investigate whether the presence of $\mathrm{Pd}^{\delta+}$ species is mainly due to the electron transfer from Pd to P25 support $[23,25,30]$ or just Pd oxidation, cyclic voltammeter (CV) studies of P25@Pd catalyst were performed. Cyclic voltammograms (Figure 5) show that there is no Pd reduction peak in the first cycle while obvious Pd reduction peak at $0.47 \mathrm{~V}$ is clearly observed in the second cycle. The results indicate that the presence of $\mathrm{Pd}^{\delta+}$ species is unlikely due to $\mathrm{Pd}$ oxidation but rather to electron transfer from Pd to P25 support, which is similar to previous literature reports $[23,25,30]$.
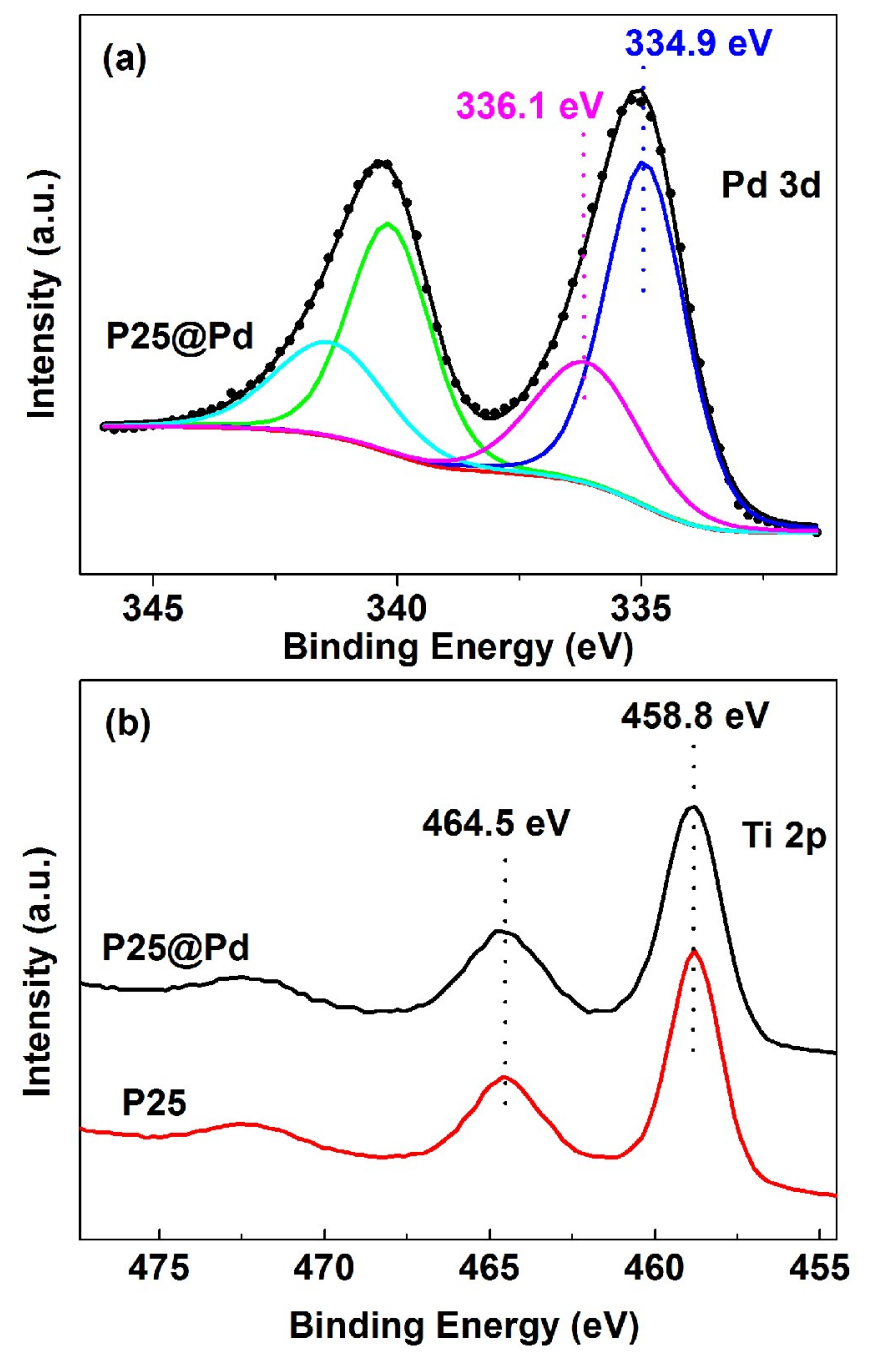

Figure 4. (a) X-ray photoelectron spectroscopy (XPS) Pd 3d spectra of P25@Pd core-shell catalyst. Circle symbols are experimental data. $\mathrm{Pd}^{0}$ peaks at $334.9 \mathrm{eV}$ and $340.2 \mathrm{eV}$, and $\mathrm{Pd}^{\delta+}$ peaks at $336.1 \mathrm{eV}$ and $341.4 \mathrm{eV}$ are fitting results. (b) XPS Ti 2p spectra of P25@Pd catalyst and P25 support. 


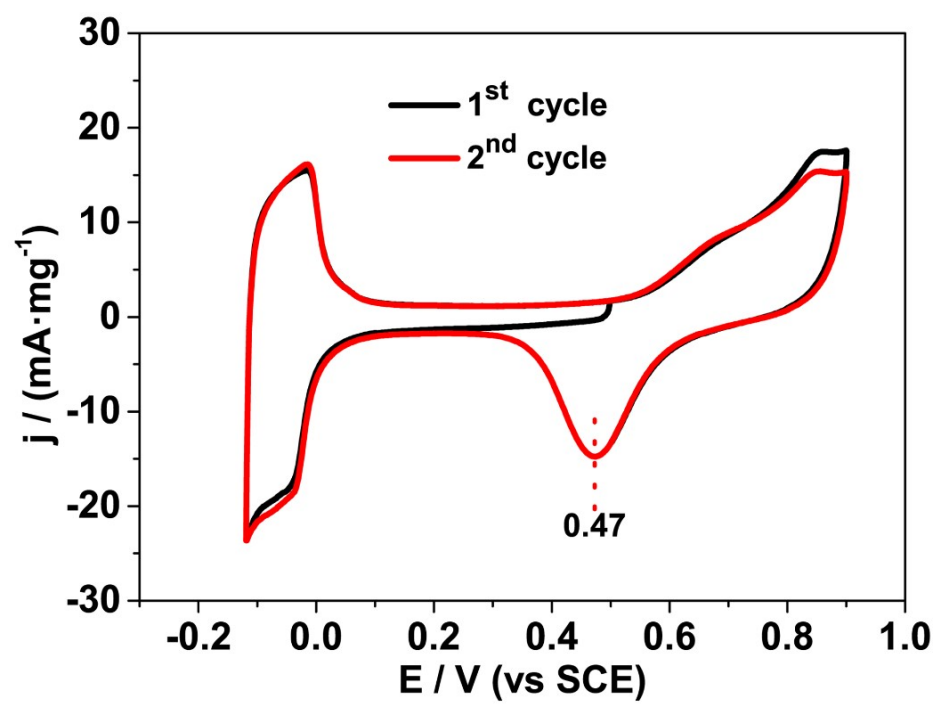

Figure 5. Cyclic voltammograms at a scanning rate of $50 \mathrm{mV} \mathrm{s}^{-1}$ measured on a glass carbon electrode modified with $\mathrm{P} 25 @ \mathrm{Pd}$ core-shell catalyst in a $0.5 \mathrm{M} \mathrm{H}_{2} \mathrm{SO}_{4}$ solution.

\subsection{Enantioselective Hydrogenation of Acetophenone}

The catalytic performance of P25@Pd catalyst was evaluated by utilizing the enantioselective hydrogenation of acetophenone as a probe reaction. As an $\alpha, \beta$-unsaturated ketone, both the aromatic ring and the carbonyl group may undergo hydrogenation. As shown in Scheme 1, the selective hydrogenation of acetophenone involves several competitive and consecutive reactions, which may produce side products such as acetylcyclohexane, ethylbenzene and 1-cyclohexylethanol in addition to the target product, 1-phenylethanol [31-33]. Therefore, it is a great challenge to develop a catalyst with both high chemoselectivity and enantioselectivity to chiral 1-phenylethanol.

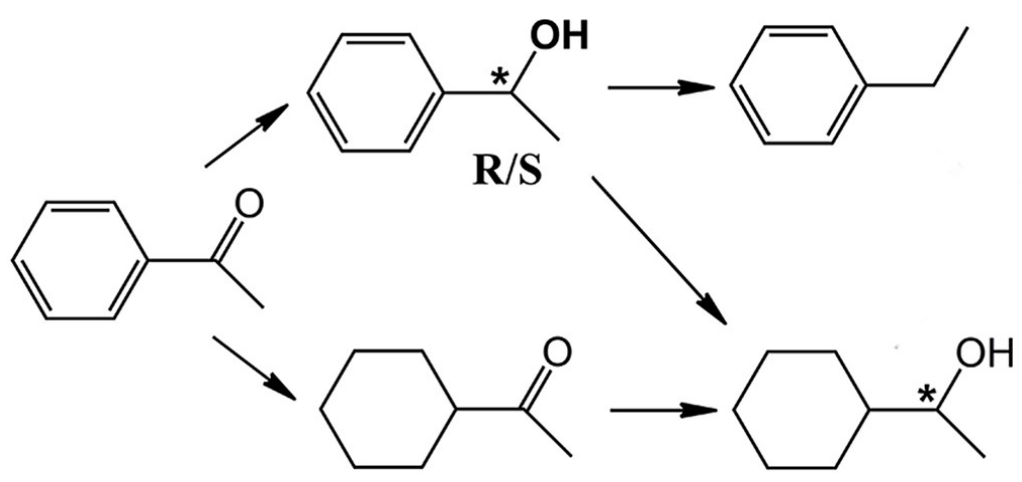

Scheme 1. Reasonable products in selective hydrogenation of acetophenone.

Figure 6 shows the catalytic performance of the P25@Pd catalyst in the enantioselective hydrogenation of acetophenone. For comparison, the catalytic behaviours of Pd/P25 with the same metal loading and unsupported Pd black catalysts were also tested under the same reaction conditions and the catalytic results are shown in Figure 6. Over P25@Pd catalyst, the yield of 1-phenylethanol increases steeply up to $\sim 100 \%$ in a reaction time of $165 \mathrm{~min}$ and then keeps unchanged at a prolonged reaction time, demonstrating the excellent selectivity of the P25@Pd catalyst to the $\mathrm{C}=\mathrm{O}$ group. Our previous study showed that, under the present reaction conditions, the liquid phase hydrogenation of acetophenone is zero-order for acetophenone [34], which is consistent with other literature reports $[35,36]$. Therefore, we calculated the reaction rate from the slope of the acetophenone conversion versus time plots based on our previous report [34]. The reaction rate is $36.5 \mathrm{mmol} \mathrm{h}^{-1}$ $\mathrm{g}_{\mathrm{Pd}}{ }^{-1}$ on P25@Pd core-shell catalyst (Table 1, Entry 1), which is 36.5 and 30.2 times that of impregnated 
Pd/P25 (1.00 $\mathrm{mmol} \mathrm{h}^{-1} \mathrm{~g}_{\mathrm{Pd}}{ }^{-1}$, Table 1, Entry 2) and Pd black catalysts $\left(1.21 \mathrm{mmol} \mathrm{h}^{-1} \mathrm{~g}_{\mathrm{Pd}}{ }^{-1}\right.$, Table 1, Entry 3), respectively, demonstrating the superior activity of the P25@Pd catalyst.

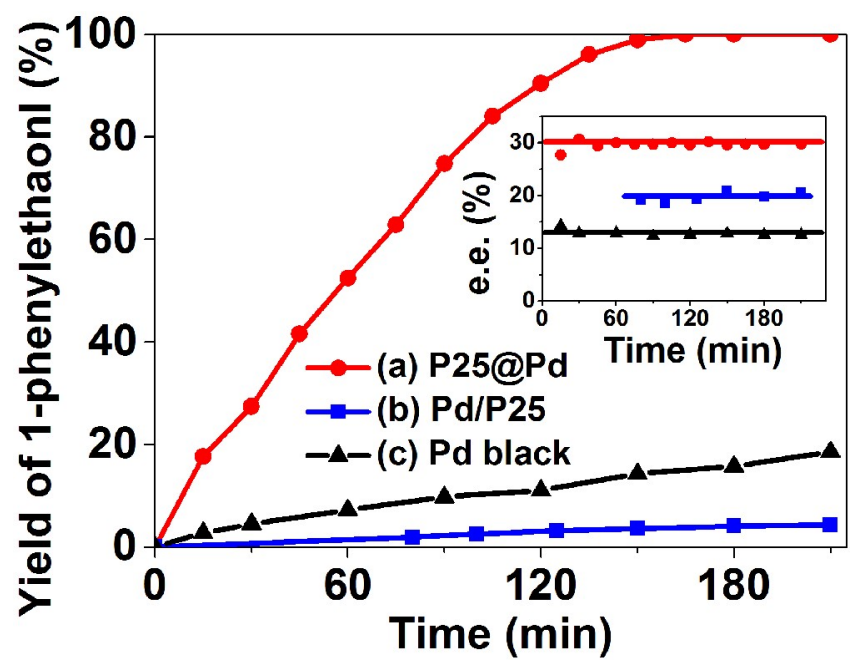

Figure 6. Catalytic results of acetophenone enantioselective hydrogenation over (a) P25@Pd, (b) Pd/P25, and (c) Pd black catalysts. Reaction conditions: $273 \mathrm{~K}, 7 \mathrm{mg}$ of catalyst, $20 \mu \mathrm{L}$ of acetophenone, $400 \mathrm{mg}$ of S-proline, $17 \mathrm{~mL}$ of methanol, and $\mathrm{H}_{2}\left(60 \mathrm{~mL} \cdot \mathrm{min}^{-1}\right)$.

Table 1. Catalytic performance of P25@Pd, Pd/P25 and Pd black catalysts in the enantioselective hydrogenation of acetophenone.

\begin{tabular}{ccccc}
\hline Entry & Catalyst & $\begin{array}{c}\text { Reaction Rate } \\
\left(\mathbf{m m o l ~ h} \mathbf{~}^{\mathbf{1}} \mathbf{g}_{\mathbf{P d}} \mathbf{- 1}\right)\end{array}$ & $\begin{array}{c}\text { e.e. } \\
\mathbf{( \% )}\end{array}$ & Dominant Enantiomer \\
\hline 1 & P25@Pd & 36.5 & 30 & $\mathrm{R}$ \\
2 & $\mathrm{Pd} / \mathrm{P} 25$ & 1.00 & 20 & $\mathrm{R}$ \\
3 & Pd black & 1.21 & 13 & $\mathrm{R}$ \\
\hline
\end{tabular}

Reaction conditions: $273 \mathrm{~K}, 7 \mathrm{mg}$ of catalyst, $20 \mu \mathrm{L}$ of acetophenone, $400 \mathrm{mg}$ of S-proline, $17 \mathrm{~mL}$ of methanol, and $\mathrm{H}_{2}$ $\left(60 \mathrm{~mL} \cdot \mathrm{min}^{-1}\right)$.

As shown in the inset of Figure 6, the impregnated Pd/P25 catalyst gives an average enantioselectivity of $\sim 20 \%$ (R-enantiomer dominant) which is similar to the value of supported $\mathrm{Pd}$ or Pt catalysts reported in literature [5-7]. Under the same reaction conditions, the P25@Pd core-shell catalyst exhibits an average enantioselectivity of 30\% (R-enantiomer dominant), which is $50 \%$ higher than that of the impregnated $\mathrm{Pd} / \mathrm{P} 25$ catalyst. The improved enantioselectivity of P25@Pd core-shell catalyst as compared to the impregnated Pd/P25 catalyst in the heterogeneous enantioselective hydrogenation of acetophenone could probably be attributed to the exclusion of negative weak interactions existing on the surface of support. As for the unsupported Pd black catalyst, the enantioselectivity is only $13 \%$ (R-enantiomer dominant), which is $43 \%$ of the value on P25@Pd core-shell catalyst. This demonstrates that the electronic properties of Pd in the P25@Pd core-shell catalyst affected by the interaction between the ultrathin Pd shell and the P25 support probably also play a positive role in the improvement of enantioselectivity. If we could further replace commercial P25 by pure anatase or rutile $\mathrm{TiO}_{2}$ support with specific facets, the electronic state of $\mathrm{Pd}$ may be tuned by changing the interaction between $\mathrm{Pd}$ and the specific $\mathrm{TiO}_{2}$ facets, which may be promising in heterogeneous enantioselective hydrogenations. 


\section{Materials and Methods}

\subsection{Chemicals and Materials}

Commercial $\mathrm{TiO}_{2}$ (Aeroxide ${ }^{\circledR} \mathrm{P} 25$ ) was purchased from ACROS (Geel, Belgium). $\gamma-\mathrm{Al}_{2} \mathrm{O}_{3}$ was purchased from Alfa Aesar (Tewksbury, MA, USA). Mesoporous carbon was synthesized based on the method reported by Ryoo et al. [37]. Palladium chloride $\left(\mathrm{PdCl}_{2}\right)$ was purchased from J\&K Scientific Ltd. (Beijing, China). Hydrochloric acid, $\mathrm{SiO}_{2}, \mathrm{~N}_{2} \mathrm{H}_{4} \cdot \mathrm{H}_{2} \mathrm{O}$ and dimethyl formamide (DMF) were purchased from Sinopharm Chemical Regent Co. Ltd. (Shanghai, China). The aqueous solution of $\mathrm{H}_{2} \mathrm{PdCl}_{4}(1.0 \mathrm{M})$ was perpared by dissovling $\mathrm{PdCl}_{2}$ in a concentrated hydrochloric acid solution.

\subsection{Catalyst Synthesis}

P25@Pd catalyst: The synthesis of the P25@Pd core-shell catalyst was based on the reduction of $\mathrm{Pd}^{\mathrm{I}}$ carbonyl complex [19]. In a typical synthesis, $40 \mathrm{mg}$ of P25 was added in $8.00 \mathrm{~mL}$ of distilled water and then ultrasonicated for $60 \mathrm{~min}$ to obtain well-dispersed P25 aqueous suspension. Next, $240 \mu \mathrm{L}$ of $\mathrm{H}_{2} \mathrm{PdCl}_{4}$ aqueous solution $(1.0 \mathrm{M})$ was added to $80 \mathrm{~mL}$ of anhydrous DMF in a three-necked glass flask at ambient temperature under stirring, and a brownish red solution was obtained. Then, carbon monoxide at atmospheric pressure with a flow rate of $100 \mathrm{~mL} \mathrm{~min}^{-1}$ was purged through the solution for $20 \mathrm{~min}$ and the brownish red solution turned bright yellow due to the reduction of $\mathrm{H}_{2} \mathrm{PdCl}_{4}$ to $\mathrm{Pd}^{\mathrm{I}}$ carbonyl complex [19]. Then, $8.00 \mathrm{~mL}$ of ultrasonicated well-dispersed aqueous suspension of P25 was added to the bright yellow solution and dark blue suspensions were formed due to the reduction of $\mathrm{Pd}^{\mathrm{I}}$ carbonyl complex to metallic Pd [19]. After $20 \mathrm{~min}$, the dark blue suspensions were centrifuged. The final catalyst was washed with methanol three times, and dried in a vacuum for activity test.

$\mathrm{Pd} / \mathrm{P} 25$ catalyst: The Pd/P25 catalyst is synthesized by a traditional impregnation method. First, $26.4 \mu \mathrm{L}$ of $\mathrm{H}_{2} \mathrm{PdCl}_{4}(1.0 \mathrm{M})$ was pipetted and diluted with $1.0 \mathrm{~mL}$ of distilled water. Then, $5 \mathrm{mg}$ of commercial P25 support was added and the mixture was ultrasonicated at ambient temperature for $1 \mathrm{~h}$. The mixture was evaporated and dried at $393 \mathrm{~K}$ for $2 \mathrm{~h}$. The resulting brown powders were reduced by $10 \mathrm{~mL}$ of aqueous solution of $\mathrm{N}_{2} \mathrm{H}_{4} \cdot \mathrm{H}_{2} \mathrm{O}(30 \%)$ with stirring at ambient conditions. The products were washed with distilled water three times and then with methanol three times. The catalyst was kept in methanol for activity test.

Pd black catalyst: $468 \mu \mathrm{L}$ of $\mathrm{H}_{2} \mathrm{PdCl}_{4}(1.0 \mathrm{M})$ was pipetted and diluted with $20 \mathrm{~mL}$ of distilled water. Then, $200 \mathrm{~mL}$ of aqueous solution of $\mathrm{N}_{2} \mathrm{H}_{4} \cdot \mathrm{H}_{2} \mathrm{O}(30 \%)$ was added dropwise under stirring at ambient conditions. The black suspensions were centrifuged and the obtained Pd black catalyst was washed with distilled water three times and then with methanol three times. The catalyst was kept in methanol for activity test.

\subsection{Characterization}

The transmission electron microscopy (TEM), the high-resolution TEM (HRTEM) images, the scanning transmission electron microscopy (STEM), and the energy dispersive X-ray emission (EDX) mapping results were obtained on a field-emission transmission electron microscope (FEI Tecnai $G^{2}$ F20 S-Twin, Hillsboro, OR, USA, $200 \mathrm{kV}$ ). The element content of catalysts was determined by inductively coupled plasma atomic emission spectroscopy (ICP-AES, Thermo Elemental IRIS Intrepid, Waltham, MA, USA). The Brunauer-Emmett-Teller (BET) specific surface areas were analyzed by $\mathrm{N}_{2}$ adsorption on a Tristar II 3020 apparatus (Norcross, GA, USA). The sample was degassed under $\mathrm{N}_{2}$ flow at $383 \mathrm{~K}$ for $2 \mathrm{~h}$ before the measurement. The X-ray diffraction (XRD) patterns were acquired on a Bruker AXS D8 Advance X-ray diffractometer (Karlsruhe, Germany, $\mathrm{Cu}-\mathrm{K} \alpha$ radiation, $\lambda=0.15418 \mathrm{~nm}, 40 \mathrm{kV}, 40 \mathrm{~mA}$ ) with a scanning rate of $1^{\circ} \mathrm{min}^{-1}$ at $2 \theta$ ranging from $20^{\circ}$ to $90^{\circ}$. X-ray photoelectron spectroscopy (XPS) was utilized to detect the electronic state of the samples on a Perkin-Elmer PHI 5000C instrument (Waltham, MA, USA, $14 \mathrm{kV}, 250 \mathrm{~W})$ with $\mathrm{Mg} \mathrm{K} \alpha(\mathrm{h} v=1253.6 \mathrm{eV})$ as the excitation source. Prior to the measurement, the samples were degassed at $298 \mathrm{~K}$ for $12 \mathrm{~h}$ in a vacuum chamber. The binding energy (BE) values were calibrated by referring to the $\mathrm{C} 1$ s peak $(284.6 \mathrm{eV})$ of contaminant carbon. 
Cyclic voltammeter (CV) with a scanning rate of $50 \mathrm{mV} \mathrm{s}^{-1}$ was performed in a $\mathrm{N}_{2}$-saturated $0.5 \mathrm{M}$ $\mathrm{H}_{2} \mathrm{SO}_{4}$ solution at ambient temperature by using a standard three-electrode electrochemical cell on a Bio-Logic science instrument (SP-300, Grenoble, France). Then, $10 \mu \mathrm{l}$ of suspension containing P25@Pd core-shell catalyst $\left(\mathrm{Pd} 0.55 \mathrm{mg} \mathrm{mL}^{-1}\right)$ was pipetted onto a polished glass carbon electrode $(\mathrm{d}=5 \mathrm{~mm})$ and dried in air at ambient temperature. Then, $5 \mu \mathrm{l}$ of Nafion solution ( $1 \mathrm{wt} . \%)$ was pipetted onto it and the Pd working electrode was obtained. A conventional three-electrode cell was used, including a saturated calomel electrode (SCE) as the reference electrode, a graphite rod as the counter electrode and the as-prepared Pd electrode as the working electrode. The Pd loading was $28 \mu \mathrm{g} \mathrm{cm}^{-2}$.

\subsection{Activity Test}

Similar to our previous report [34], the liquid phase enantioselective hydrogenation of acetophenone was carried out at $273 \mathrm{~K}$ in a three-necked glass flask under atmospheric $\mathrm{H}_{2}$ pressure $\left(60 \mathrm{~mL} \cdot \mathrm{min}^{-1}\right)$. First, $400 \mathrm{mg}$ of S-proline and $7 \mathrm{mg}$ of catalyst were dispersed in $17 \mathrm{~mL}$ of methanol. Then, $20 \mu \mathrm{L}$ of reactant acetophenone was pipetted into the mixture. The reaction was stirred with a rate of $1000 \mathrm{rpm}$ for the elimination of diffusion effects. In the reaction process, the supernatant was sampled at intervals and detected with a gas chromatography (Agilent 7820A, Waltham, MA, USA) equipped with a chiral capillary column (CP-CHIRASIL-Dex CB, $25 \mathrm{~m} \times 0.25 \mu \mathrm{m} \times 0.32 \mathrm{~mm}$ ) and a flame ionization detector (FID). The retention times of products were identified with the standard chemicals. The enantiomeric excess was expressed as e.e. $\%=|(R-S)| /(R+S) \times 100$.

\section{Conclusions}

P25@Pd core-shell catalyst with an ultrathin Pd shell of ca. $1 \mathrm{~nm}$ and a high Pd loading of $\sim 36 \mathrm{wt} . \%$ was successfully prepared by a facile strategy under mild conditions based on the reduction of $\mathrm{Pd}^{\mathrm{I}}$ carbonyl complex on the surface of the P25 support. By excluding the negative weak interactions existing on the surface of the support, the P25@Pd core-shell catalyst exhibits higher activity and enantioselectivity than that of the impregnated Pd/P25 catalyst in the enantioselective hydrogenation of acetophenone. The much higher enantioselectivity over the P25@Pd core-shell catalyst than that on unsupported Pd black catalyst indicates that the presence of the P25 core is necessary to affect the electronic properties of $\mathrm{Pd}$, which also probably have a positive effect on the enantioselectivity. The work provides understanding for the designed synthesis of effective enantioselective supported metal catalyst for heterogeneous asymmetric catalysis, which also opens up a new strategy for the synthesis of supported noble-metal catalyst with both high metal loading and well-dispersed metal.

Author Contributions: Conceptualization, X.C and X.G.; investigation, X.G., L.H. and J.X.; writing-original draft preparation, X.G. and X.C.; writing-review and editing, X.C. and H.H.; supervision, X.C. and H.H.; project administration, X.C. and H.H.; funding acquisition, X.C.

Funding: This research was funded by the National Natural Science Foundation of China, grant number $21573045,21773034$.

Conflicts of Interest: The authors declare no conflict of interest.

\section{References}

1. Blaser, H.U.; Pugin, B. Scope and Limitations of the Application of Heterogeneous Enantioselective Catalysis. In Chiral Reactions in Heterogeneous Catalysis; Jannes, G., Dubois, V., Eds.; Plenum Press: New York, NY, USA, 1995; pp. 33-57, ISBN 978-1-4615-1909-6.

2. Baiker, A. Crucial Aspects in the Design of Chirally Modified Noble Metal Catalysts for Asymmetric Hydrogenation of Activated Ketones. Chem. Soc. Rev. 2015, 44, 7449-7464. [CrossRef] [PubMed]

3. Meemken, F.; Baiker, A. Recent Progress in Heterogeneous Asymmetric Hydrogenation of $\mathrm{C}=\mathrm{O}$ and $\mathrm{C}=\mathrm{C}$ Bonds on Supported Noble Metal Catalysts. Chem. Rev. 2017, 117, 11522-11569. [CrossRef] [PubMed]

4. Klabunovskii, E.; Smith, G.V.; Zsigmond, Á. Heterogeneous Enantioselective Hydrogenations-Theory and Practice; Springer: Dordrecht, The Netherlands, 2006; pp. 161-170, ISBN 978-1-4020-4296-6. 
5. Tungler, A.; Tarnai, T.; Mathe, T.; Petro, J. Enantioselective Hydrogenation of Acetophenone in the Presence of S-proline. J. Mol. Catal. 1991, 67, 277-282. [CrossRef]

6. Hess, R.; Vargas, A.; Mallat, T.; Bürgi, T.; Baiker, A. Inversion of Enantioselectivity in the Platinum-catalyzed Hydrogenation of Substituted Acetophenones. J. Catal. 2004, 222, 117-128. [CrossRef]

7. Vetere, V. New Approach toward the Synthesis of Asymmetric Heterogeneous Catalysts for Hydrogenation Reactions. J. Catal. 2004, 226, 457-461. [CrossRef]

8. Mills, P.L.; Ramachandran, P.A.; Chaudhari, R.V. Multiphase Reaction-engineering for Fine Chemicals and Pharmaceuticals. Rev. Chem. Eng. 1992, 8, 1-176. [CrossRef]

9. Perosa, A.; Tundo, P.; Selva, M. Multiphase Heterogeneous Catalytic Enantioselective Hydrogenation of Acetophenone over Cinchona-modified Pt/C. J. Mol. Catal. A Chem. 2002, 180, 169-175. [CrossRef]

10. Mhadgut, S.; Torok, M.; Esquibel, J.; Torok, B. Highly Asymmetric Heterogeneous Catalytic Hydrogenation of Isophorone on Proline Modified Base-supported Palladium Catalysts. J. Catal. 2006, 238, 441-448. [CrossRef]

11. Kubota, T.; Kubota, H.; Kubota, T.; Moriyasu, E.; Uchida, T.; Nitta, Y.; Sugimura, T.; Okamoto, Y. Enantioselective Hydrogenation of (E)- $\alpha$-phenylcinnamic Acid over Cinchonidine-modified Pd Catalysts Supported on $\mathrm{TiO}_{2}$ and $\mathrm{CeO}_{2}$. Catal. Lett. 2009, 129, 387-393. [CrossRef]

12. Chen, Z.; Guan, Z.; Li, M.; Yang, Q.; Li, C. Enhancement of the Performance of a Platinum Nanocatalyst Confined within Carbon Nanotubes for Asymmetric Hydrogenation. Angew. Chem. Int. Ed. 2011, 50, 4913-4917. [CrossRef]

13. Guan, Z.H.; Lu, S.M.; Li, C. Enantioselective Hydrogenation of $\alpha, \beta$-unsaturated Carboxylic Acid over Cinchonidine-modified Pd Nanoparticles Confined in Carbon Nanotubes. J. Catal. 2014, 311, 1-5. [CrossRef]

14. Bui Trung, T.S.; Kim, Y.; Kang, S.; Lee, H.; Kim, S. The Enantioselective Hydrogenation of (E)- $\alpha$-phenylcinnamic Acid: Role of $\mathrm{TiO}_{2}$ Coated on $\mathrm{Al}_{2} \mathrm{O}_{3}$ as a Novel Support for Cinchonidine-modified Pd Catalysts. Catal. Commun. 2015, 66, 21-24. [CrossRef]

15. Li, C. Chiral Synthesis on Catalysts Immobilized in Microporous and Mesoporous Materials. Catal. Rev. Sci. Eng. 2004, 46, 419-492. [CrossRef]

16. Hoxha, F.; Schimmoeller, B.; Cakl, Z.; Urakawa, A.; Mallat, T.; Pratsinis, S.E.; Baiker, A. Influence of Support Acid-base Properties on the Platinum-catalyzed Enantioselective Hydrogenation of Activated Ketones. J. Catal. 2010, 271, 115-124. [CrossRef]

17. Chaudhuri, R.G.; Paria, S. Core/Shell Nanoparticles: Classes, Properties, Synthesis Mechanisms, Characterization, and Applications. Chem. Rev. 2012, 112, 2373-2433. [CrossRef]

18. Zhang, L.; Zhou, N.; Wang, B.; Liu, C.; Zhu, G. Fabrication of $\mathrm{Fe}_{3} \mathrm{O}_{4} / \mathrm{PAH} / \mathrm{PSS} @ P d$ Core-shell Microspheres by Layer-by-layer Assembly and Application in Catalysis. J. Colloid Interface Sci. 2014, 421, 1-5. [CrossRef] [PubMed]

19. Li, H.; Chen, G.X.; Yang, H.Y.; Wang, X.L.; Liang, J.H.; Liu, P.X.; Chen, M.; Zheng, N.F. Shape-controlled Synthesis of Surface-clean Ultrathin Palladium Nanosheets by Simply Mixing a Dinuclear Pd ${ }^{\mathrm{I}}$ Carbonyl Chloride Complex with $\mathrm{H}_{2} \mathrm{O}$. Angew. Chem. Int. Ed. 2013, 52, 8368-8372. [CrossRef] [PubMed]

20. Huang, X.Q.; Tang, S.H.; Mu, X.L.; Dai, Y.; Chen, G.X.; Zhou, Z.Y.; Ruan, F.X.; Yang, Z.L.; Zheng, N.F. Freestanding Palladium Nanosheets with Plasmonic and Catalytic Properties. Nat. Nanotechnol. 2011, 6, 28-32. [CrossRef]

21. He, M.; Ji, J.; Liu, B.Y.; Huang, H.B. Reduced $\mathrm{TiO}_{2}$ with Tunable Oxygen Vacancies for Catalytic Oxidation of Formaldehyde at Room Temperature. Appl. Surf. Sci. 2019, 473, 934-942. [CrossRef]

22. Tauster, S.J.; Fung, S.C.; Garten, R.L. Strong Metal-support Interactions. Group 8 Noble Metals Supported on $\mathrm{TiO}_{2}$. J. Am. Chem. Soc. 1978, 100, 170-175. [CrossRef]

23. Kovtunov, K.V.; Barskiy, D.A.; Salnikov, O.G.; Burueva, D.B.; Khudorozhkov, A.K.; Bukhtiyarov, A.V.; Prosvirin, I.P.; Gerasimov, E.Y.; Bukhtiyarov, V.I.; Koptyug, I.V. Strong Metal-support Interactions for Palladium Supported on $\mathrm{TiO}_{2}$ Catalysts in the Heterogeneous Hydrogenation with Parahydrogen. ChemCatChem 2015, 7, 2581-2584. [CrossRef]

24. Shen, W.J.; Okumura, M.; Matsumura, Y.; Haruta, M. The Influence of the Support on the Activity and Selectivity of Pd in CO Hydrogenation. Appl. Catal. A Gen. 2001, 213, 225-232. [CrossRef]

25. Tapin, B.; Epron, F.; Especel, C.; Ly, B.K.; Pinel, C.; Besson, M. Study of Monometallic $\mathrm{Pd}_{/} \mathrm{TiO}_{2}$ Catalysts for the Hydrogenation of Succinic Acid in Aqueous Phase. ACS Catal. 2013, 3, 2327-2335. [CrossRef]

26. Lu, M.H.; Du, H.; Wei, B.; Zhu, J.; Li, M.S.; Shan, Y.H.; Song, C.S. Catalytic Hydrodeoxygenation of Guaiacol over Palladium Catalyst on Different Titania Supports. Energy Fuels 2017, 31, 10858-10865. [CrossRef] 
27. Xiang, Q.; Lv, K.; Yu, J. Pivotal Role of Fluorine in Enhanced Photocatalytic Activity of Anatase $\mathrm{TiO}_{2}$ Nanosheets with Dominant (001) Facets for the Photocatalytic Degradation of Acetone in Air. Appl. Catal. B Environ. 2010, 96, 557-564. [CrossRef]

28. Chen, X.B.; Liu, L.; Yu, P.Y.; Mao, S.S. Increasing Solar Absorption for Photocatalysis with Black Hydrogenated Titanium Dioxide Nanocrystals. Science 2011, 331, 746-750. [CrossRef]

29. Wang, G.; Wang, H.; Ling, Y.; Tang, Y.; Yang, X.; Fitzmorris, R.C.; Wang, C.; Zhang, J.Z.; Li, Y. Hydrogen-treated $\mathrm{TiO}_{2}$ Nanowire Arrays for Photoelectrochemical Water Splitting. Nano Lett. 2011, 11, 3026-3333. [CrossRef]

30. Li, Y.B.; Zhang, C.B.; Ma, J.Z.; Chen, M.; Deng, H.; He, H. High Temperature Reduction Dramatically Promotes $\mathrm{Pd} / \mathrm{TiO}_{2}$ Catalyst for Ambient Formaldehyde Oxidation. Appl. Catal. B Environ. 2017, 217, 560-569. [CrossRef]

31. Masson, J.; Cividino, P.; Court, J. Selective Hydrogenation of Acetophenone on Chromium Promoted Raney Nickel Catalysts. III. The Influence of the Nature of the Solvent. Appl. Catal. A Gen. 1997, 161, 191-197. [CrossRef]

32. Bergault, I.; Fouilloux, P.; Joly-Vuillemin, C.; Delmas, H. Kinetics and Intraparticle Diffusion Modelling of a Complex Multistep Reaction: Hydrogenation of Acetophenone over a Rhodium Catalyst. J. Catal. 1998, 175, 328-337. [CrossRef]

33. Fujita, S.-I.; Onodera, Y.; Yoshida, H.; Arai, M. Selective Hydrogenation of Acetophenone with Supported $\mathrm{Pd}$ and Rh Catalysts in Water, Organic Solvents, and $\mathrm{CO}_{2}$-dissolved Expanded Liquids. Green Chem. 2016, 18, 4934-4940. [CrossRef]

34. Su, N.; Gao, X.Y.; Chen, X.Y.; Yue, B.; He, H.Y. The Enantioselective Hydrogenation of Acetophenone over Pd Concave Tetrahedron Nanocrystals Affected by the Residual Adsorbed Capping Agent Polyvinylpyrrolidone (PVP). J. Catal. 2018, 367, 244-251. [CrossRef]

35. Aramendia, M.A.; Borau, V.; Gomez, J.F.; Herrera, A.; Jimenez, C.; Marinas, J.M. Reduction of Acetophenones over Pd/AlPO 4 Catalysts. Linear Free Energy Relationship (LFER). J. Catal. 1993, 140, 335-343. [CrossRef]

36. Drelinkiewicz, A.; Waksmundzka, A.; Makowski, W.; Sobczak, J.W.; Krol, A.; Zieba, A. Acetophenone Hydrogenation on Polymer-palladium Catalysts. The Effect of Polymer Matrix. Catal. Lett. 2004, 94, 143-156. [CrossRef]

37. Jun, S.; Joo, S.H.; Ryoo, R.; Kruk, M.; Jaroniec, M.; Liu, Z.; Ohsuna, T.; Terasaki, O. Synthesis of New, Nanoporous Carbon with Hexagonally Ordered Mesostructure. J. Am. Chem. Soc. 2000, 122, 10712-10713. [CrossRef] 